\title{
МЕТОДЫ ПСИХОЛОГИЧЕСКОЙ КОРРЕКЦИИ ЭМОЦИОНАЛЬНЫХ СОСТОЯНИЙ ДЕТЕЙ-СИРОТ
}

\section{METHODS OF PSYCHOLOGICAL CORRECTION OF EMOTIONAL STATES OF ORPHANED CHILDREN}

A. Igovskaya V. Akhmetova

Summary:The article is devoted to the methods of psychological correction of emotional States of orphans. The features of the deprivation social situation of the development of children and adolescents in residential institutions are revealed. The features of the emotional development of orphaned children, which are based on parental deprivation, are described. Methods of psychological correction of emotional States of teenagers brought up in residential institutions are substantiated. The effectiveness of individual and group methods of psychological correction of emotional States of adolescents brought up in residential institutions within the framework of comprehensive support programs is shown.

Keywords: orphanhood, deprivation, pathological emotional reactions, psychological correction.

Иговская Анна Станиславовна к.м.н.; дочент, Российский университет дружбы народов igovskaya@gmail.com

Ахметова Валерия Валерьевна к.м.н., дочент, Российский университет дружбы народов lera-axmetova@yandex.ru

Аннотация: Статья посвящена вопросам методов психологической коррекции эмоциональных состояний детей-сирот. Раскрыты особенности депривационной социальной ситуации развития детей и подростков в учреждениях интернатного типа. Описаны особенности эмоционального развития детейсирот, в основе которых лежит родительская депривация. Обоснованы методы психологической коррекции эмоциональных состояний подростков, воспитывающихся в интернатных учреждениях. Показана эффективность индивидуальных и групповых методов психологической коррекции патологических эмоциональных реакций подростков, воспитывающихся в интернатных учреждениях, в рамках комплексных программ сопровождения.

Ключевые слова: сиротство, депривация, патологические эмоциональные реакции, психологическая коррекция.

сглаженности эмоций и чувств при склонности к страхам и тревоге; поведенческие отклонения в форме частых реакций активного и пассивного протеста, недостатка чувства дистанции в общении или, наоборот, затруднения при общении [6].

Специфические расстройства эмоциональной сферы наблюдаются у детей и подростков, воспитывающихся в учреждениях интернатного типа. У детей и подростков данной категории понижается общий психический тонус, нарушаются процессы саморегуляции, доминирует пониженное настроение, формируются чувства тревоги и неуверенности в себе, пропадает заинтересованное отношение к окружающему миру. Ухудшается эмоциональная регуляция, эмоционально-познавательные взаимодействия, тормозится интеллектуальное развитие. Качественно иную форму имеет и развитие самооценки и всех аспектов «Я», то есть представления о себе, отношения к себе, образа «Я». Низкая самооценка, характерная для воспитанников интернатных учреждений, является основой формирования личностных отклонений и невротических расстройств [6]. Согласно исследованию Т.И. Шульги, дети-сироты, чаще, чем их сверстники из семей, обладают низким уровнем эмпатии, низким уровнем эмоционального и социального интеллекта [7]. Зарубежными исследователями показано, что дети и под- 
ростки, живущие в детских домах, имеют более высокие уровни тревожно-депрессивных расстройств, отличаются чрезмерной чувствительностью к критике, склонностью к поведенческим и соматическим расстройствам [8].

Итак, у подростков, воспитывающихся в детских домах, адаптационные возможности ниже по сравнению со сверстниками, воспитывающимися в семьях, что демонстрирует высокий риск социально-психологической дезадаптации. Подростки с низкими адаптивными показателями характеризуются выраженными эмоциональными реакциями тревожно-астенического спектра. Основными показателями перехода эмоциональных реакций в патологические являются распространение реакции за пределы той микросреды, где они возникли, присоединение невротических расстройств, которые проявляются в колебаниях настроения, раздражительности, в истощенности, в нарушении сна, в соматовегетативных расстройствах.

Описанные особенности эмоционального развития подростков и детей, оставшихся без попечения родителей, воспитывающихся в учреждениях интернатного типа, вызывают необходимость проведения психологической коррекции в процессе их психосоциального развития. Психологическая коррекция определяется как «особый вид психологической помощи, систему психологических и психотерапевтических воздействий, целью которых является предупреждение и преодоление отклонений в психическом развитии, обусловленных как внутренней спецификой психического дизонтогенеза, так и средовыми факторами» [4, с. 25].

Сегодня в практике оказания психологической помощи детям и подросткам, воспитывающимся в учреждениях интернатного типа, реализуются комплексные программы психолого-педагогического сопровождения, которые отличаются, как по содержанию, так и по используемым методам коррекционного воздействия. Перечень возможных психологических программ сопровождения детей-сирот, включающих вариативные коррекционные формы и методы работы, представлен в исследовании С.В. Лактионовой. К ним относятся программы личностного роста, коммуникативной компетентности, формирования лидерства, формирования толерантности, эффективного взаимодействия, коррекции отклоняющегося поведения, коррекции агрессивности, формирования здорового образа жизни, развития эмоциональной устойчивости и др. [2].

В самом общем виде в комплексных программах пси- холого-педагогического сопровождения детей-сирот выделяют профилактическое, диагностическое, коррекционно-развивающее, реабилитационное и консультативное направления работы. Описывая диагностическое и коррекционно-развивающее направления деятельности специалистов, В.Н. Гуров, В.Ф. Вишняков, отмечают необходимость проведения психологического обследования каждого воспитанника с целью мониторинга развития, прогнозирования девиаций и разработки индивидуальных коррекционно-развивающих программ, включающих психотерапевтическую помощь, направленных на коррекцию и развитие личности ребенка [1].

В этой связи интерес вызывают используемые в комплексных программах сопровождения методы психологической коррекции эмоциональных патологических реакций у детей и подростков, воспитывающихся в интернатных учреждениях. Выбор коррекционных методов зависит от многих факторов и, прежде всего, от характера эмоциональных расстройств, причин их возникновения и индивидуальных особенностей детей и подростков, воспитывающихся в учреждениях интернатного типа. Эффективными методами психологической коррекции являются методы арт-терапии, рисуночные техники, арт-терапевтические техники «масок», фитотерапии [3]. Показали свою эффективность и групповые методы коррекции в форме коррекционно-развивающих занятий и психологических тренингов, индивидуальные психологические консультации с применением вариативных приемов и методов психокоррекции: арттерапии, телесной терапии, гештальтпсихологии, рациональной терапии.

С целью мониторинга результативности используемых методов психологической коррекции в рамках комплексных программ сопровождения подростков, воспитывающихся в учреждениях интернатного типа, было проведено исследование динамики эмоциональных состояний в ходе реализации программ. Мониторинг эмоциональных состояний проводился в 2016-2019 г. на базе Черновского детского дома-школы, на базе ГОУ № 1, 2, 3, 5 для детей-сирот и детей, оставшихся без попечения родителей, Забайкальский край, г. Чита среди воспитанников подросткового возраста от 12 до 17 лет. Результаты исследования показали, что внедрение индивидуальных и групповых методов коррекции эмоциональных состояний в форме индивидуальных программ сопровождения, коррекционно-развивающих занятий и психологических тренингов способствуют снижению тревожности, враждебности, конфликтности и гармонизации эмоционального фона настроения у подростков, воспитывающихся в интернатных учреждениях. 


\section{ЛИТЕРАТУРА}

1. Гуров В.Н. Реформирование системы обеспечения жизнедеятельности, воспитания и обучения детей-сирот и детей, оставшихся без попечения родителей / В.Н. Гуров, В.Ф. Вишняков. Ставрополь, 2003. - С. $42-44$.

2. Лактионова С.В. Социально-профессиональная адаптация выпускников сиротских учреждений: дис. ... кандидата педагогических наук. - СанктПетербург, 2008. - 235 c.

3. Лебедева Л.Д. Практика арт-терапии: подходы, диагностика, система занятий. - СПб.: Речь, 2003. - 256 с.

4. Слюсарева Е.С. Психологическая готовность специального психолога к психокоррекционной работе с детьми: монография. - Ставрополь: Изд-во СГПИ, 2010. -152 c.

5. Социально-педагогические технологии семейного устройства и воспитания детей-сирот и детей, оставшихся без попечения родителей: Учеб.-метод. пособие / Под ред. Г.И. Климантовой. - М.: Изд-во РГСУ, 2008. - 192 с.

6. Толстых Н.Н., Прихожан А.М. Работа психолога в учреждениях интернатного типа для детей, оставшихся без попечения родителей.// Психологическая наука и образование. - 2009. - № 3. - С. 5-12.

7. Шульга Т.И. Социально-психологические проблемы выпускников учреждений для детей-сирот и детей, оставшихся без попечения родителей // Вестник Московского государственного областного университета. 2013. №3. С. 68-75.

8. Simsek Z., Erol N., Oztop D., Munir K. Prevalence and predictors of emotional and behavioral problems reported by teachers among institutionally reared children and adolescents in Turkish orphanages compared with community controls // Children and Youth Services Review. - 2007. - Vol. 29 (7). - P. 883-889.

( ) Иговская Анна Станиславовна (igovskaya@gmail.com), Ахметова Валерия Валерьевна (lera-axmetova@yandex.ru).

Журнал «Современная наука: актуальные проблемы теории и практики»

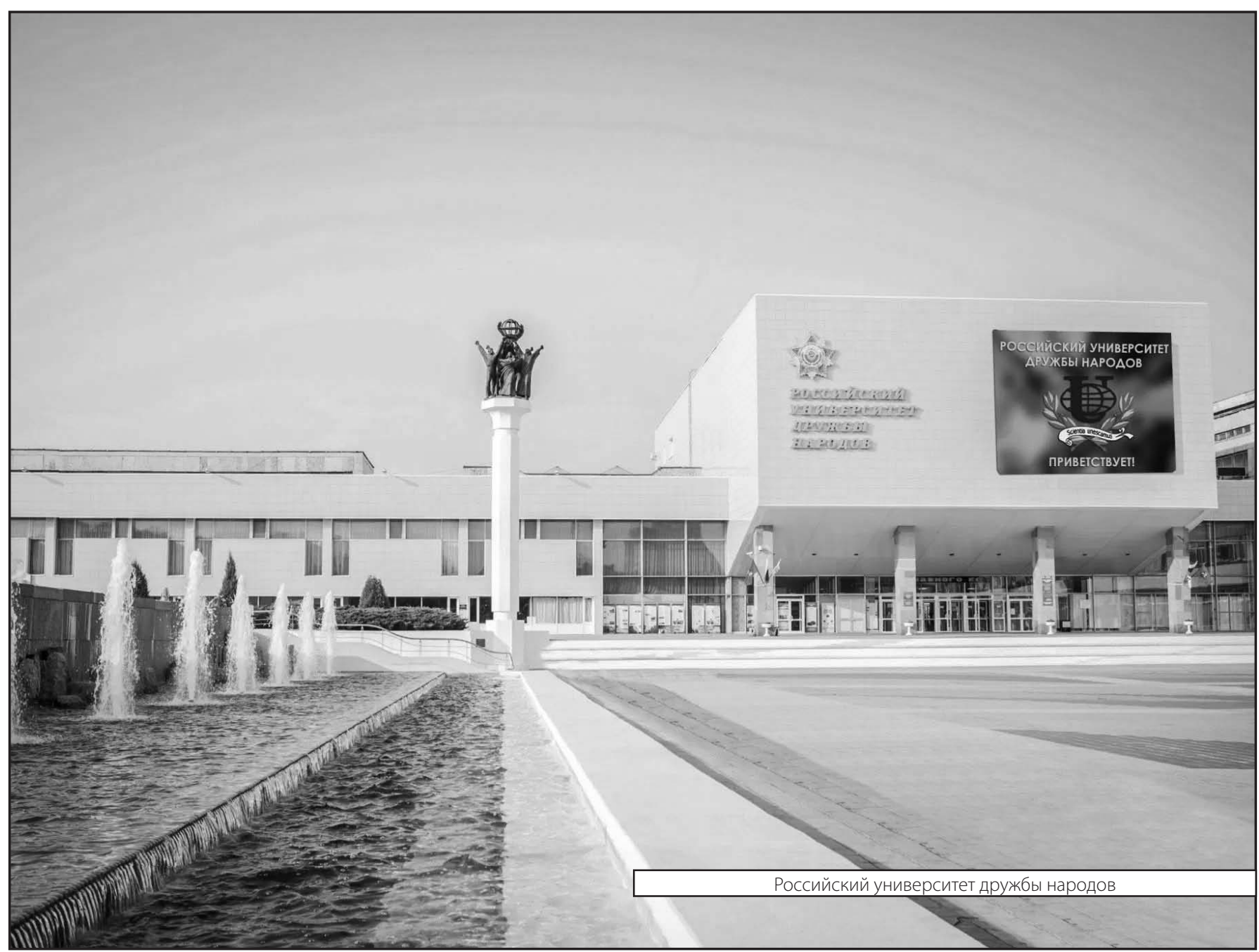

